Article

\title{
Impact of Cover Crop Monocultures and Mixtures on Organic Carbon Contents of Soil Aggregates
}

\author{
Daphne Topps ${ }^{1}$, Md Imam ul Khabir ${ }^{1}$, Hagir Abdelmagid ${ }^{1}$, Todd Jackson ${ }^{1}$, Javed Iqbal ${ }^{2}$, Boakai K. Robertson ${ }^{1}$, \\ Zahida Hassan Pervaiz ${ }^{3}$ and Muhammad Saleem ${ }^{1, *} *$ \\ 1 Department of Biological Sciences, Alabama State University, Montgomery, AL 36101, USA; \\ dtopps@alasu.edu (D.T.); mkhabir5218@myasu.alasu.edu (M.I.u.K.); \\ habdelmagid5758@myasu.alasu.edu (H.A.); j.todd92498@gmail.com (T.J.); brobertson@alasu.edu (B.K.R.) \\ 2 Department of Agronomy and Horticulture, University of Nebraska-Lincoln, Lincoln, NE 68583, USA; \\ javed.iqbal@unl.edu \\ 3 Department of Biological Sciences, Auburn University, Auburn, AL 36849, USA; zhp0006@auburn.edu \\ * Correspondence: msaleem@alasu.edu
}

check for updates

Citation: Topps, D.; Khabir, M.I.u.; Abdelmagid, H.; Jackson, T.; Iqbal, J.; Robertson, B.K.; Pervaiz, Z.H.; Saleem, M. Impact of Cover Crop Monocultures and Mixtures on Organic Carbon Contents of Soil Aggregates. Soil Syst. 2021, 5, 43. https://doi.org/10.3390/

soilsystems 5030043

Academic Editor: Heike Knicker

Received: 16 July 2021

Accepted: 3 August 2021

Published: 6 August 2021

Publisher's Note: MDPI stays neutral with regard to jurisdictional claims in published maps and institutional affiliations.

Copyright: (c) 2021 by the authors. Licensee MDPI, Basel, Switzerland. This article is an open access article distributed under the terms and conditions of the Creative Commons Attribution (CC BY) license (https:/ / creativecommons.org/licenses/by/ $4.0 /)$.

\begin{abstract}
Cover crops are considered an integral component of agroecosystems because of their positive impacts on biotic and abiotic indicators of soil health. At present, we know little about the impact of cover crop types and diversity on the organic carbon (OC) contents of different soil aggregate-size classes. In this study, we investigated the effect of cover plant diversity on OC contents of different soil aggregates, such as macro- $(<2000-500 \mu \mathrm{m})$, meso- $(<500-250 \mu \mathrm{m})$, and micro-aggregates $(<250 \mu \mathrm{m})$. Our experiment included a total of 12 experimental treatments in triplicate; six different monoculture treatments such as chickling vetch (Vicia villosa), crimson clover (Trifolium incarnatum), hairy vetch (Vicia villosa), field peas (Pisum sativum), oilseed radish (Raphanus sativus), and mighty mustard (Brassica juncea), and their three- and six-species mixture treatments, including one unplanted control treatment. We performed this experiment usingdeep pots that contained soil collected from a corn-soybean rotation field. At vegetative maturity of cover plants (about 70 days), we took soil samples, and the soil aggregate-size classes were separated by the dry sieving. We hypothesized that cover crop type and diversity will improve OC contents of different soil aggregate-size classes. We found that cover plant species richness weakly positively increased OC contents of soil macro-aggregates $(p=0.056)$, whereas other aggregate-size classes did not respond to cover crop diversity gradient. Similarly, the OC contents of macroaggregates varied significantly $(p=0.013)$ under cover crop treatments, though neither monoculture nor mixture treatments showed significantly higher OC contents than the control treatment in this short-term experiment. Interestingly, the inclusion of hairy vetch and oilseed radish increased and decreased the OC contents of macro- and micro-aggregates, respectively. Moreover, we found a positive correlation between shoot biomass and OC contents of macroaggregates. Overall, our results suggest that species-rich rather than -poor communities may improve OC contents of soil macroaggregates, which constitute a major portion of soil systems, and are also considered as important indicators of soil functions.
\end{abstract}

Keywords: cover crops; soil organic carbon; soil aggregate-size classes; soil health; cover crop monocultures; cover crop mixtures

\section{Introduction}

Cover or service crops are an important component of agroecosystems, while their positive effects on soil health are acknowledged in recent studies. These crops are planted in the bare-fallow between two major commodity crops, for example, such as between, corn and soybean, and cotton and corn [1,2]. The vegetation cover by service plants may improve soil biological, physical, and chemical properties [3-5]. The cover crops include both legumes and grasses, while these crops may enhance the storage of carbon and 
nitrogen in the soil, which is important for soil health and crop productivity [6,7]. For instance, the plantation of rye (Secale cereale L.) and hairy vetch (Visia villosa) decreased soil bulk density and improved total porosity, aggregate stability, and plant available water contents $[8,9]$. The leguminous cover crops can increase soil nitrogen contents, and thus may improve the nutrition of the next crop [10]. Similarly, the adoption of cover crops substantially improved the near-surface soil organic carbon (OC) contents, infiltration, and aggregate stability [11], and reduced the no-till-induced near-surface soil compaction [12]. The effects of cover crops on agroecosystem services depend, among other things, on crop species identity, mixture composition, soil properties, and climatic conditions $[9,13]$.

Soil aggregation is an essential indicator of soil health and productivity. The physical component of soil is characterized by different aggregate-size classes, ranging from micro- to macro-aggregates. Classically, soil aggregates are classified into macro-aggregates $(>0.25 \mathrm{~mm})$ and micro-aggregates $(<0.25 \mathrm{~mm})$ [4]. The different soil aggregate-size classes demonstrate distinct physical, chemical, and biological properties, including the contents of OC. The OC contents of soil determine the sustainability and resilience of the agroecosystems, and are linked with multiple parameters of soil health and crop productivity $[14,15]$. The aggregation of soil particles into different aggregate-size classes may improve the potential of soil to retain carbon, essential nutrients, and moisture [16,17]. In particularl, the OC can improve soil aggregation and thus aggregate stability. The OC input may lead to macroaggregation by improving the binding forces between soil microaggregates and other smaller particles [18].

The soil macroaggregates are very complex bodies, and mostly they carry labile organic material and young OC [14]. The positive impact of cover crops on the OC contents of soil aggregates should nevertheless suggest their role in soil carbon storage, because the decomposition rates of carbon are decreased with the size of different aggregate size classes [17]. Some studies have reported positive effects of management practices on soil aggregation and OC contents of different aggregate-size classes. For instance, among cover crops, the millet cover crop increased soil capacity to accumulate labile OC in the macroaggregates and microaggregates [19]. The different soil aggregate-size classes may have different impacts on OC contents. For instance, macro-aggregates demonstrated a greater impact on the OC storage in goosegrass soils, and the micro-aggregates showed a greater impact on storage of OC under Calopogonium plantation [5]. There are also studies that have not reported the impact of cover cropping on OC contents of the soil. For instance, very interestingly, Schaefer et al. (2020) found no significant difference in the bulk OC between the cover and no cover crop fields after one season [17]. Due to the discrepancy in the effect of cover crops on OC contents of different aggregate-size classes, it is important to elucidate the impact of cover crop monocultures and mixtures on OC contents of different soil aggregate-size classes.

Following the biodiversity and ecosystem function theory, we hypothesize that an increase in cover crop species richness may positively impact OC contents of different aggregate-size classes. Second, we also hypothesize that cover crop species identity and mixture combinations may also influence the OC contents of different aggregate-size classes. Third, considering the competition among cover crops in the mixture treatments, we anticipate that cover plant shoot (biomass) and root (biomass, length, area) traits will also demonstrate a correlation with OC contents of different soil aggregate-size classes.

\section{Materials and Methods}

\subsection{Soil and Cover Crop Species}

The complete experimental protocol about this experiment is recently reported [4]. Briefly, six different cover crops species such as chickling vetch (Vicia villosa), crimson clover (Trifolium incarnatum), hairy vetch (Vicia villosa), field peas (Pisum sativum), oilseed radish (Raphanus sativus), and mighty mustard (Brassica juncea) were used in the current study. These are popular cover crops, which are commonly grown in different parts of the United States. We purchased organic seeds from Johnny Seeds@. We collected topsoil (classified 
as Kenesaw-Coly silt loam) using a shovel from an agricultural field under soybean-corn rotation, which was located in Axtell, Nebraska. The soil samples were processed and plant residues such as roots and other litter were manually removed. This soil was then sieved through a $>2000 \mu \mathrm{m}$ sieve ( $2 \mathrm{~mm}$ sieve). The soil analysis revealed the following soil properties: $\mathrm{pH} 7.2$; total OC $0.98 \%$; organic matter $2.7 \%$; potassium $557 \mathrm{mg} \mathrm{kg}^{-1}$; nitrate$\mathrm{N} 31.16 \mathrm{mg} \mathrm{kg}^{-1}$; calcium $2714 \mathrm{mg} \mathrm{kg}^{-1}$; sulfate-S $22.53 \mathrm{mg} \mathrm{kg}^{-1}$; sodium $42 \mathrm{mg} \mathrm{kg}^{-1}$; magnesium $478 \mathrm{mg} \mathrm{kg}^{-1}$; phosphorus $58 \mathrm{mg} \mathrm{kg}^{-1}$ (Mehlich P-III); and cation exchange capacity (CEC) $19 \mathrm{me} / 100 \mathrm{~g}$ [4].

\subsection{Experimental Setup and Soil Sampling}

We mixed sieved soil with vermiculite and playground sand at 3:2:3 ratios, respectively, in order to promote root growth and soil aggregation by plants. The mixture soil was added into the deep pots that had the following dimensions: depth, $35.56 \mathrm{~cm}$; and diameter, $6.35 \mathrm{~cm}$. Following substitute experimental design (implying that initial plant seeding density was kept the same across monoculture and mixture treatments), we planted monoculture and mixtures of different cover crops (Table 1), and plants were grown in a greenhouse set at $23.3^{\circ} \mathrm{C}$ under unfertilized conditions [4]. The experimental period was about 70 days (April-June) during summer. The plants were watered as needed, with a minimal application twice per week, with tap water. We harvested plants and collected soil samples at vegetative maturity. The soil collected was sieved to various aggregatesize classes, mainly macro- $(<2000-500 \mu \mathrm{m})$, meso- $(<500-250 \mu \mathrm{m})$, and micro-aggregates $(<250 \mu \mathrm{m})$ [4]. Before that, roots were removed with forceps. All aggregate-size classes were kept in $50 \mathrm{~mL}$ falcon tubes and kept at room temperature till OC analysis. Before OC analysis, the samples of different soil aggregate-size classes were treated with acid to remove different forms of carbonates (e.g., inorganic carbon), thus leaving the OC for quantification. After this, the $\mathrm{OC}$ contents were determined using the resistance furnace method [20]. Briefly, the soil samples were ignited in an oxygen-rich combustion chamber at $1350{ }^{\circ} \mathrm{C}$. Then, the aliquot of combustion gas was passed through the infrared absorption detector to determine the OC contents. Further details about OC analysis can be found in previous studies $[4,21,22]$.

Table 1. An overview of cover crop species monoculture and mixture treatments.

\begin{tabular}{cccc}
\hline Sr. & Combinations & Abbreviation & Treatment Type \\
\hline 1. & Control & $\mathrm{C}$ & Un-planted \\
2. & Crimson clover & $\mathrm{CC}$ & Monoculture \\
3. & Chickling vetch & Monoculture \\
4. & Field peas & Monoculture \\
5. & Hairy vetch & $\mathrm{H}$ & Monoculture \\
6. & Mighty mustard & $\mathrm{M}$ & Monoculture \\
7. & Oilseed radish & $\mathrm{O}$ & Monoculture \\
8. & Field peas + Hairy vetch + Mustard & PHM & Three-species mixture \\
9. & Mustard + Hairy vetch + Crimson clover & MHC & Three-species mixture \\
10. & Oilseed radish + Crimson clover + Chickling vetch & OCCh & Three-species mixture \\
11. & Oilseed radish + Chickling vetch + Field peas & OChP & Three-species mixture \\
12. & All species mixture & All & 6-species mixture \\
\hline
\end{tabular}

\section{Data Analysis}

As described elsewhere, all experimental treatments were performed in triplicate. To determine the significant differences in the OC contents of soil aggregates across various cover crop treatments, we used ANOVA followed by Fisher's test. To determine the relationship between the cover crop species richness and OC contents of macroaggregates, we used general linear regression followed by ANOVA. The relationship between shoot biomass and OC contents of macroaggregates was determined by general linear regression followed by ANOVA. The general linear-regression analysis was performed to determine 
the trends of OC contents of macro- and micro-aggregates across cover plant richness gradient. Meanwhile, we also performed ANOVA followed by Fisher's post hoc test to determine significant differences among OC contents of macro- and micro-aggregates at different cover plant richness gradients. All data were analyzed in the Minitab v16 and PC-Ord v6.

\section{Results}

\subsection{Impact of Cover Crop Monocultures and Mixtures on OC Contents of Soil Aggregates}

We determined OC contents of micro-, meso- and macro-aggregates at the end of our experiment. The OC contents of macroaggregates differed significantly across cover crop treatments, ranging from monoculture to mixtures, though we did not observe significant differences in OC contents of meso-and microaggregates (Figure 1A-C). Regarding OC contents of macroaggregates, some monoculture treatments showed even lower OC contents than the control treatments (e.g., hairy vetch). However, mustard, field peas, and some mixture combinations showed relatively higher OC contents, though these were not significantly higher than the control treatment (Figure 1).

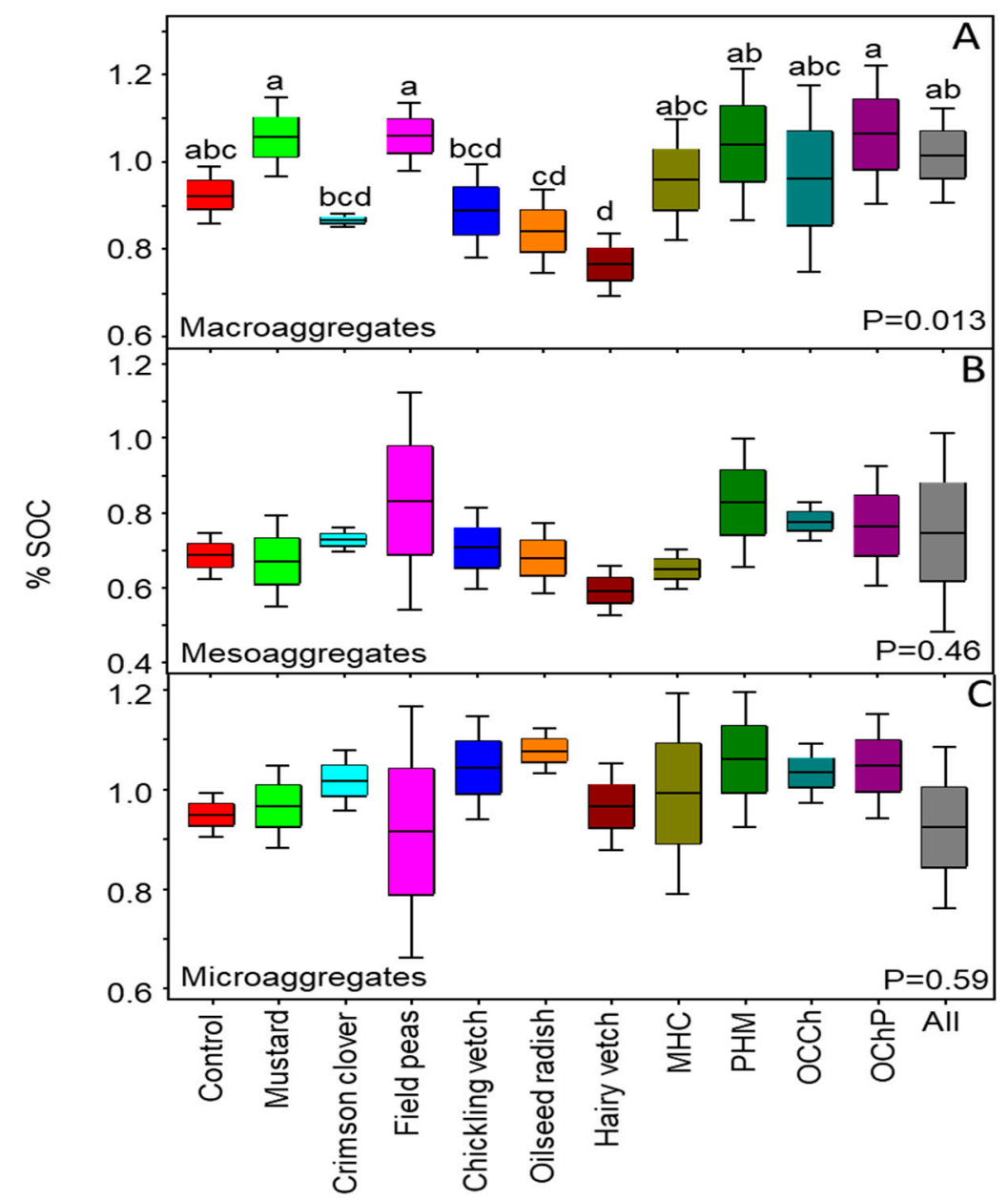

Figure 1. Impact of cover crop monocultures and mixtures on OC contents of different soil macroaggregates (A), mesoaggregates $(\mathbf{B})$ and microaggregates $(\mathbf{C})$. Error bars represent means \pm 1 1SE. The lack of shared letters above the bars indicates a significant difference.

\subsection{Impact of Cover Crop Diversity Gradient on OC Contents of Different Soil Aggregate-Size Classes}

The impact of cover crop diversity gradient on OC contents of micro-, meso, and macroaggregates was tested. We only found a marginally significant impact of cover crop species richness on OC contents of macroaggregates (Figure 2), though OC contents of other 
aggregate size classes did not respond to the diversity gradient. Among plant traits, the shoot biomass of cover plants positively correlated with OC contents of macroaggregates $(p=0.049)$. The effects of each cover crop monoculture and its corresponding mixtures (with other species) on OC contents of the different aggregate-size classes were plotted to compare the monoculture and mixture performance. In most of the cases, cover crop monocultures did not improve OC contents of different aggregate-size classes (Figure 1A-C). However, we found significant effects of cover crop diversity gradients, which included the effects of hairy vetch and its corresponding mixtures on OC contents of macro-aggregates (Figure 3A). In contrast, the cover crop species gradients which included oilseed radish reduced the OC contents of microaggregates (Figure $3 \mathrm{~B}$ ).
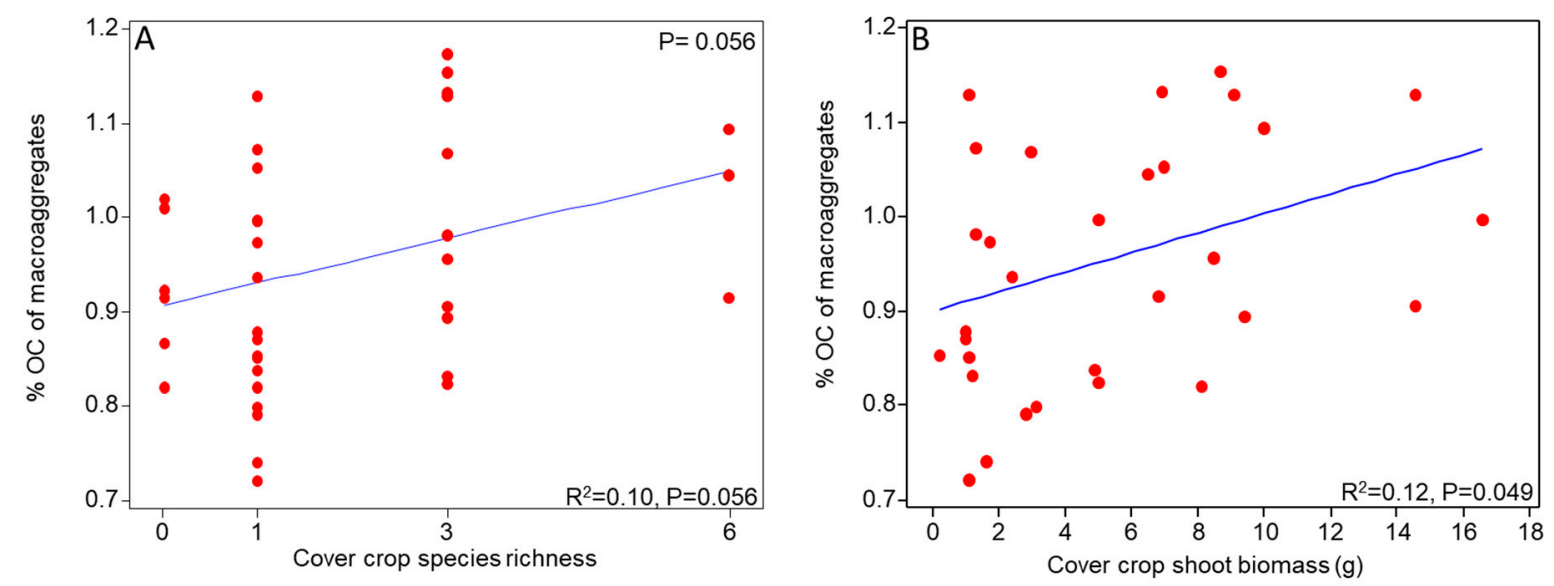

Figure 2. Impact of cover crop species richness on OC contents of soil macroaggregates (A). The relationship between cover plant shoot biomass and OC contents of soil macroaggregates $(\mathbf{B})$.
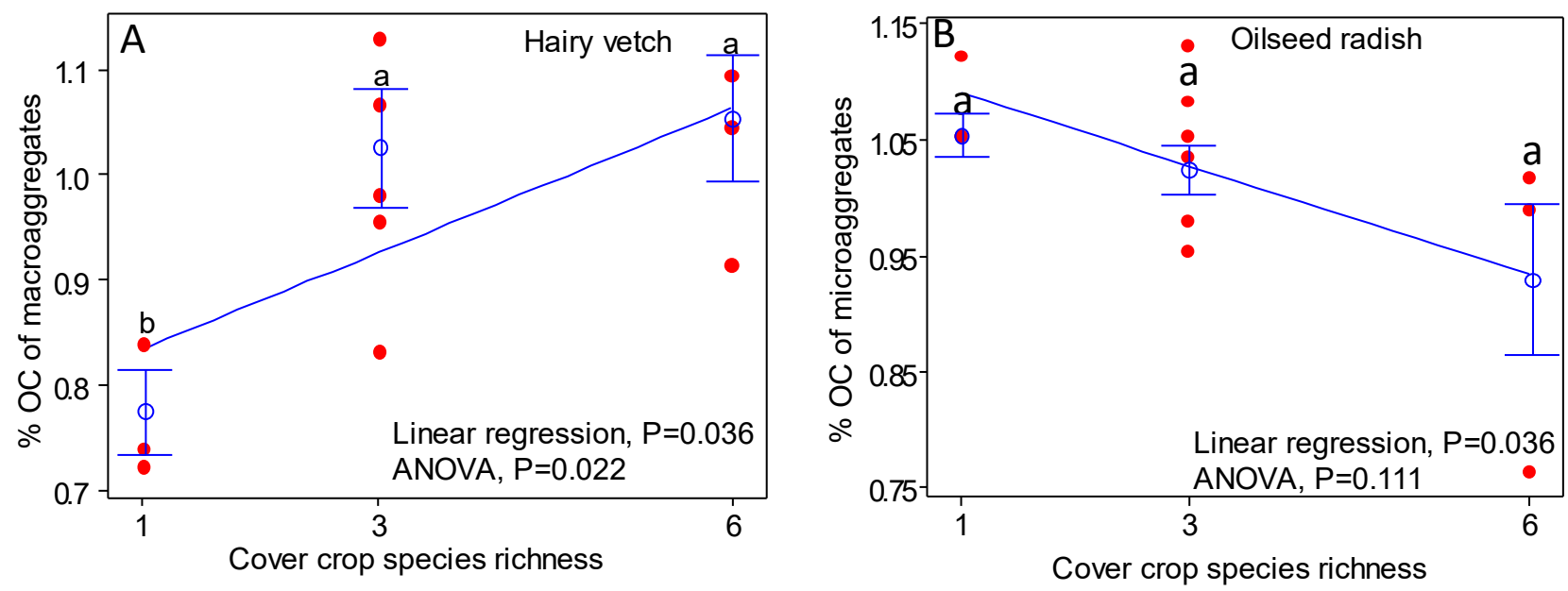

Figure 3. Individually comparing the OC contents of macrooaggregates (A) and microaggregates (B) under hairy vetch and oilseed radish against their corresponding 3 - and 6-species mixtures across the cover plant diversity gradients. The red-filled circles represent data points of different replicates, while the empty blue circles reflect the mean point of data at respective richness levels. We are providing both linear regression and ANOVA results for a better understanding of the comparison between mixtures and monocultures in influencing the OC contents of macroaggregates and microaggregates. The error bars represent means \pm 1SE whereas the lack of shared letters above the bars represents significant differences across different richness levels.

\subsection{Comparing OC Contents among Different Aggregate-Size Classes in Cover Crop Monocultures and Mixture Treatments}

The OC contents of different aggregate-size classes under monoculture and mixture treatments were compared. First of all, we observed significant differences among OC 
contents in the control treatment (un-planted). Both macro- and micro-aggregates showed higher OC contents than meso-aggregates. Moreover, some monocultures, such as mustard, hairy vetch, chickling vetch, and some mixtures, such as $\mathrm{PHM}, \mathrm{OChP}, \mathrm{OCCh}$, and $\mathrm{MHC}$ also showed the same patterns of OC contents across different aggregate-size classes. However, interestingly, under one best performing monoculture such as field peas and six-species mixture, the soil aggregate-size classes did not differ in their OC contents (Figure 4).
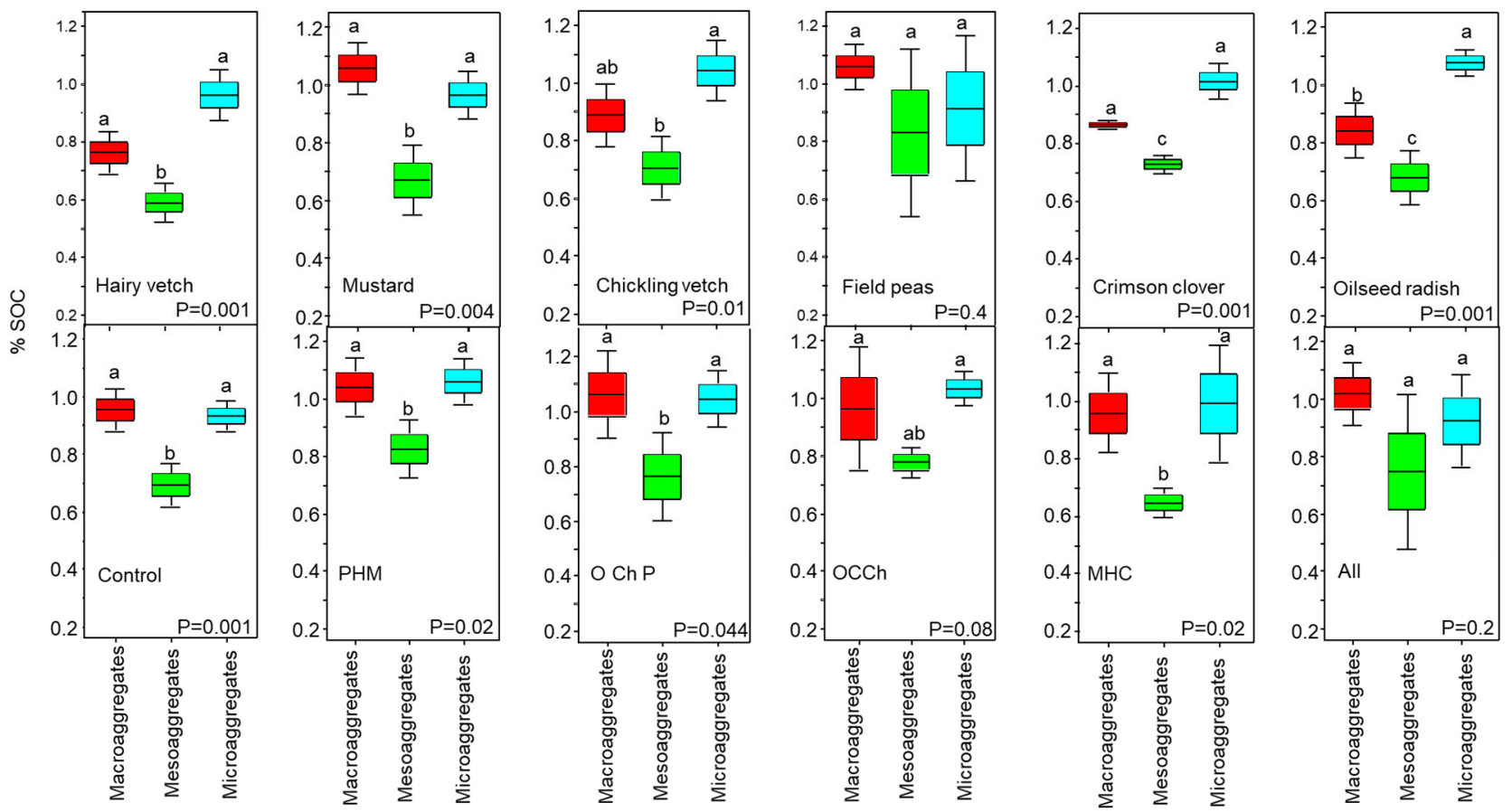

Figure 4. The OC contents of different soil aggregate-size classes under various cover crop treatments. Error bars represent means $\pm 1 S E$, and the lack of shared letters above the bars reflects a significant difference.

\section{Discussion}

Agricultural soils are highly complex and heterogeneous ecosystems, which are comprised of an intricate organization of soil aggregates that determine soil porosity for water, nutrient, and gaseous exchange. Though organic substances regulate the aggregation of soil mineral particles into macro- and microaggregates, these aggregates also influence the soil biological properties, retention, and storage of OC under a broad range of soil, environmental, and climatic conditions. The soil aggregates are essential for soil health, fertility, and productivity [23,24]. The tremendous diversity and size variations in different soil aggregate classes, in terms of their orientation, distribution, architectural complexity, and physicochemical features, create highly favorable and distinct microhabitats for microbial communities that could determine the functioning and resilience of soil ecosystems to environmental and climatic factors $[25,26]$. Therefore, considering the positive role of cover crops in soil health, it is important to study their role in influencing the OC contents of different soil aggregate-size classes [27]. Cover crops that are grasses or legumes may influence the structural properties of the soils, including the OC contents of different soil aggregate-size classes. Thus in this study we report the impact of cover crop monocultures and mixtures on the OC of macro-, meso-, and micro-aggregates.

The cover crop treatments more substantially altered the OC contents of soil macroaggregates than that of meso- and micro-aggregates (Figure 1A-C), thus suggesting that cover crops might have improved soil aggregation [4] and, as a result, the OC contents of these aggregates. The positive effects of cover crops on the OC contents of macroaggregates are reported in some previous studies. Mendes et al. (1999) reported that mineralizable contents of carbon in differed aggregate-size classes differed under cover crop treatments [28]. Moreover, Udom and Omovbude (2019) showed that grass cover crops improved OC con- 
tents of macroaggregates in the Guinea soils [5]. However, Veloso et al. (2019) reported that the cropping systems with two legume cover crops showed a strong carbon enrichment in the microaggregates of the superficial soil layer as compared to soil with no legume cover crop [14]. The different responses of soil aggregate-size classes to monoculture and mixture treatments might be attributed to their different microbial communities, plant inputs, and decomposition rates of OC in soil [29]. Moreover, we found a substantial effect of cover crop diversity gradient on OC contents of macroaggregates, which nevertheless, supports the prediction of biodiversity theory stating that increases in species diversity may improve ecosystem function (here in our case, OC contents). Previously several studies have reported the positive effect of cover crops and plant diversity gradient on soil properties, including their OC contents $[4,30]$, but our results, for the first time, report the impact of cover crop species richness on OC contents of macroaggregates. Although we initially anticipated a correlation between root traits (biomass, length, area) and OC contents of different soil aggregates, we did not find any correlation between them (data not shown). However, interestingly, shoot biomass showed a positive correlation between OC contents of soil macroaggregates (Figure 2B). Previously, some studies have reported a positive correlation between shoot biomass and different soil properties, such as nutrient contents, microbial diversity, and aggregation [31,32]. However, we are not aware of any study that has ever reported any correlation between plant aboveground and belowground traits and OC contents of soil macroaggregates and macroaggregates. However, the poor correlation between root traits and OC contents of soil aggregates could be due to, among other things, our inability to fully extract roots from soil, and profile their biomass and architectural traits. Therefore, aboveground biomass might be a good predictor of cover plant effects on belowground soil properties, including the OC contents of macroaggregates. Overall, our results predict the role of cover crops in improving OC contents of macroaggregates, while several studies have reported the role of soil macroaggregates in carbon sequestration and influencing the soil biological properties [33,34].

Moreover, the OC contents of monocultures and their corresponding mixtures across diversity gradients were plotted to determine whether mixtures performed better or worse in improving OC contents of different soil aggregate-size classes (Figure 3). The mixtures of hairy vetch with other species consistently performed better than its monocultures in terms of improving OC contents of soil macroaggregates. However, contrasting results were observed for oilseed radish because its mixtures reduced the OC contents of microaggregates. These results suggest that cover crop monocultures and mixtures might have contrasting effects on OC contents of soil aggregate-size classes. Previously some studies have reported contrasting results regarding cover plant species on soil properties [35,36], whereas our results suggest that cover crop interactions with soil may depend on crop and soil aggregate types.

Finally, the patterns of OC contents of different aggregate-size classes were compared across monoculture and mixture treatments. Interestingly, the OC contents of different soil aggregate-size classes varied significantly in the control treatment, in the sense that macro- and micro-aggregates had higher OC contents than meso-aggregates. Previously, several studies have shown differences in the OC contents of different soil aggregate types depending on soil and climate types [18,37-39]. The plantation of monoculture cover crops such as mustard, hairy vetch, chickling vetch, and some cover crop mixtures (PHM, $\mathrm{OChP}, \mathrm{OCCh}, \mathrm{MHC}$ ) also did not alter patterns of OC contents in different soil aggregate types, thus suggesting their weaker impacts on OC contents of different aggregate-size classes. Nevertheless, some best performing monoculture cover crops, such as field peas and highly diverse cover crop mixtures (six-species mixture), largely altered the patterns of OC contents in the soil aggregate-size classes (Figure 4), in the sense that OC contents did not vary in different soil aggregate-size classes, in contrast to what we observed under control and other treatments. These results, nevertheless, highlight the significance of best-performing monoculture cover crop and species-rich mixtures in influencing the OC contents of soil aggregates. 


\section{Conclusions and Limitations}

Cover cops are known to positively impact soil properties, and thus their integration into cropping systems is considered important for restoring and maintaining soil health. We studied the impact of different cover monocultures and mixtures on the OC contents of different soil aggregate-size classes under greenhouse conditions. Though our study suggests that cover crops may improve OC contents of soil macroaggregates, our study has some limitations that we also acknowledge. First, our study was conducted in seminatural soil under greenhouse conditions, and thus cover crop impacts on aggregate-size classes of natural soils should be investigated to validate the findings of this study. Second, the duration of our experiment was short and it was limited to one growing cyclin (till maturity) of cover crops studied, and we did not mix crop residues into the soil that could also influence the OC contents of the soil. Third, dry-sieving and fractionation of soil particles might have influenced the OC contents of sampled aggregate-size classes, and thus disturbance-free methods should be used to test the effects of cover crops on OC contents of different soil aggregate-size classes. This experiment followed the diversityfunctioning approach to test the impact of cover crop diversity on OC contents of the soil aggregates. However, future studies should aim to investigate the significance of multiple cycles of crop growth, and their impacts on other carbon pools, such as the active carbon pool, mineralizable $\mathrm{C}$, and other attributes of carbon-cycling (microbial biomass $\mathrm{C}, \mathrm{N}, \mathrm{P}$, and other nutrients). Moreover, it requires further investigatio to test different compatible and meaningful combinations of cover crop mixtures and their effects on soil physicochemical and biological properties under real-world field conditions.

Author Contributions: Conceptualization, M.S., Z.H.P., D.T. and J.I.; methodology, M.S., Z.H.P., D.T. and J.I.; software, M.S., Z.H.P., D.T. and J.I.; validation, M.S., Z.H.P., D.T. and J.I.; formal analysis, M.S., Z.H.P., D.T. and J.I.; investigation, M.I.u.K., H.A., T.J. and B.K.R.; resources, M.I.u.K., H.A., T.J. and B.K.R.; data curation, M.S., Z.H.P., D.T. and J.I.; writing-original draft preparation, M.S., Z.H.P., D.T. and J.I.; writing—review and editing, M.I.u.K., H.A., T.J. and B.K.R.; visualization, M.I.u.K., H.A., T.J. and B.K.R.; supervision, M.S., Z.H.P. and J.I.; project administration, M.S.; funding acquisition, M.S. All authors have read and agreed to the published version of the manuscript.

Funding: Financial support for this work was provided by the National Science Foundation EPSCoR Center for Root and Rhizobiome Innovation Award OIA-1557417.

Institutional Review Board Statement: Not applicable.

Informed Consent Statement: Not applicable.

Data Availability Statement: The data presented in this study are available on request.

Acknowledgments: We appreciate the help of undergraduate students who helped during the preparation of this work. We are highly grateful to three anonymous reviewers and academic editor for their very valuable comments, suggestions, and recommendations that helped us improve the quality of this manuscript.

Conflicts of Interest: The authors declare no conflict of interest.

\section{References}

1. Blanco-Canqui, H.; Shaver, T.M.; Lindquist, J.L.; Shapiro, C.A.; Elmore, R.W.; Francis, C.A.; Hergert, G.W. Cover Crops and Ecosystem Services: Insights from Studies in Temperate Soils. Agron. J. 2015, 107, 2449-2474. [CrossRef]

2. Kaye, J.P.; Quemada, M. Using Cover Crops to Mitigate and Adapt to Climate Change. A Review. Agron. Sustain. Dev. 2017, 37, 4. [CrossRef]

3. Pervaiz, Z.H.; Iqbal, J.; Zhang, Q.; Chen, D.; Wei, H.; Saleem, M. Continuous Cropping Alters Multiple Biotic and Abiotic Indicators of Soil Health. Soil Syst. 2020, 4, 59. [CrossRef]

4. Saleem, M.; Pervaiz, Z.H.; Contreras, J.; Lindenberger, J.H.; Hupp, B.M.; Chen, D.; Zhang, Q.; Wang, C.; Iqbal, J.; Twigg, P. Cover Crop Diversity Improves Multiple Soil Properties via Altering Root Architectural Traits. Rhizosphere 2020, 16, 100248. [CrossRef]

5. Udom, B.E.; Omovbude, S. Soil Physical Properties and Carbon/Nitrogen Relationships in Stable Aggregates under Legume and Grass Fallow. Acta Ecol. Sin. 2019, 39, 56-62. [CrossRef] 
6. Bolinder, M.A.; Crotty, F.; Elsen, A.; Frac, M.; Kismányoky, T.; Lipiec, J.; Tits, M.; Tóth, Z.; Kätterer, T. The Effect of Crop Residues, Cover Crops, Manures and Nitrogen Fertilization on Soil Organic Carbon Changes in Agroecosystems: A Synthesis of Reviews. Mitig. Adapt. Strateg. Glob. Chang. 2020, 25, 929-952. [CrossRef]

7. Ball, K.R.; Baldock, J.A.; Penfold, C.; Power, S.A.; Woodin, S.J.; Smith, P.; Pendall, E. Soil Organic Carbon and Nitrogen Pools Are Increased by Mixed Grass and Legume Cover Crops in Vineyard Agroecosystems: Detecting Short-Term Management Effects Using Infrared Spectroscopy. Geoderma 2020, 379, 114619. [CrossRef]

8. Adetunji, A.T.; Ncube, B.; Mulidzi, R.; Lewu, F.B. Management Impact and Benefit of Cover Crops on Soil Quality: A Review. Soil Tillage Res. 2020, 204, 104717. [CrossRef]

9. Haruna, S.I.; Anderson, S.H.; Udawatta, R.P.; Gantzer, C.J.; Phillips, N.C.; Cui, S.; Gao, Y. Improving Soil Physical Properties through the Use of Cover Crops: A Review. Agrosystems Geosci. Environ. 2020, 3, e20105. [CrossRef]

10. Thorup-Kristensen, K.; Magid, J.; Jensen, L.S. Catch Crops and Green Manures as Biological Tools in Nitrogen Management in Temperate Zones; Elsevier: Amsterdam, The Netherlands, 2003; pp. 227-302.

11. Blanco-Canqui, H.; Mikha, M.M.; Presley, D.R.; Claassen, M.M. Addition of Cover Crops Enhances No-Till Potential for Improving Soil Physical Properties. Soil Sci. Soc. Am. J. 2011, 75, 1471-1482. [CrossRef]

12. Nouri, A.; Lee, J.; Yin, X.; Tyler, D.D.; Saxton, A.M. Thirty-Four Years of No-Tillage and Cover Crops Improve Soil Quality and Increase Cotton Yield in Alfisols, Southeastern USA. Geoderma 2019, 337, 998-1008. [CrossRef]

13. Alonso-Ayuso, M.; Gabriel, J.L.; Quemada, M. The Kill Date as a Management Tool for Cover Cropping Success. PLoS ONE 2014, 9, e109587. [CrossRef] [PubMed]

14. Veloso, M.G.; Cecagno, D.; Bayer, C. Legume Cover Crops under No-Tillage Favor Organomineral Association in Microaggregates and Soil C Accumulation. Soil Tillage Res. 2019, 190, 139-146. [CrossRef]

15. Powlson, D.S.; Stirling, C.M.; Thierfelder, C.; White, R.P.; Jat, M.L. Does Conservation Agriculture Deliver Climate Change Mitigation through Soil Carbon Sequestration in Tropical Agro-Ecosystems? Agric. Ecosyst. Environ. 2016, 220, 164-174. [CrossRef]

16. Tisdall, J.M.; Oades, J.M. Organic Matter and Water-Stable Aggregates in Soils. J. Soil Sci. 1982, 33, 141-163. [CrossRef]

17. Schaefer, M.V.; Bogie, N.A.; Rath, D.; Marklein, A.R.; Garniwan, A.; Haensel, T.; Lin, Y.; Avila, C.C.; Nico, P.S.; Scow, K.M.; et al Effect of Cover Crop on Carbon Distribution in Size and Density Separated Soil Aggregates. Soil Syst. 2020, 4, 6. [CrossRef]

18. Blanco-Canqui, H.; Lal, R. Mechanisms of Carbon Sequestration in Soil Aggregates. Crit. Rev. Plant Sci. 2004, $23,481-504$. [CrossRef]

19. Silva, A.d.N.; de Figueiredo, C.C.; de Carvalho, A.M.; dos Santos Soares, D.; dos Santos, D.C.R.; da Silva, V.G. Effects of Cover Crops on the Physical Protection of Organic Matter and Soil Aggregation. Aust. J. Crop. Sci. 2016, 10, 1623-1629. [CrossRef]

20. Merry, R.H.; Spouncer, L.R. The Measurement of Carbon in Soils Using a Microprocessor-controlled Resistance Furnace. Commun. Soil Sci. Plant Anal. 1988, 19, 707-720. [CrossRef]

21. Massey, M.S.; Davis, J.G.; Ippolito, J.A.; Sheffield, R.E. Effectiveness of Recovered Magnesium Phosphates as Fertilizers in Neutral and Slightly Alkaline Soils. Agron. J. 2009, 101, 323-329. [CrossRef]

22. Rosenzweig, S.T.; Fonte, S.J.; Schipanski, M.E. Intensifying Rotations Increases Soil Carbon, Fungi, and Aggregation in Semi-Arid Agroecosystems. Agric. Ecosyst. Environ. 2018, 258, 14-22. [CrossRef]

23. Amézketa, E. Soil Aggregate Stability: A Review. J. Sustain. Agric. 1999, 14, 83-151. [CrossRef]

24. Bronick, C.J.; Lal, R. Soil Structure and Management: A Review. Geoderma 2005, 124, 3-22. [CrossRef]

25. Mustafa, A.; Minggang, X.; Ali Shah, S.A.; Abrar, M.M.; Nan, S.; Baoren, W.; Zejiang, C.; Saeed, Q.; Naveed, M.; Mehmood, K.; et al. Soil Aggregation and Soil Aggregate Stability Regulate Organic Carbon and Nitrogen Storage in a Red Soil of Southern China. J. Environ. Manag. 2020, 270, 110894. [CrossRef]

26. Moitinho, M.R.; Fernandes, C.; Truber, P.V.; Marcelo, A.V.; Corá, J.E.; da Silva Bicalho, E. Arbuscular Mycorrhizal Fungi and Soil Aggregation in a No-Tillage System with Crop Rotation. J. Plant Nutr. Soil Sci. 2020, 183, 482-491. [CrossRef]

27. Blaud, A.; van der Zaan, B.; Menon, M.; Lair, G.J.; Zhang, D.; Huber, P.; Schiefer, J.; Blum, W.E.H.; Kitzler, B.; Wei, E.H.; et al. The Abundance of Nitrogen Cycle Genes and Potential Greenhouse Gas Fluxes Depends on Land Use Type and Little on Soil Aggregate Size. Appl. Soil Ecol. 2018, 125, 1-11. [CrossRef]

28. Mendes, I.C.; Bandick, A.K.; Dick, R.P.; Bottomley, P.J. Microbial Biomass and Activities in Soil Aggregates Affected by Winter Cover Crops. Soil Sci. Soc. Am. J. 1999, 63, 873-881. [CrossRef]

29. Sarker, J.R.; Singh, B.P.; Cowie, A.L.; Fang, Y.; Collins, D.; Dougherty, W.J.; Singh, B.K. Carbon and Nutrient Mineralisation Dynamics in Aggregate-Size Classes from Different Tillage Systems after Input of Canola and Wheat Residues. Soil Biol. Biochem. 2018, 116, 22-38. [CrossRef]

30. Lamb, E.G.; Kennedy, N.; Siciliano, S.D. Effects of plant species richness and evenness on soil microbial community diversity and function. Plant Soil 2011, 338, 483-495. [CrossRef]

31. Sahib, M.R.; Pervaiz, Z.H.; Williams, M.A.; Saleem, M.; DeBolt, S. Rhizobacterial species richness improves sorghum growth and soil nutrient synergism in a nutrient-poor greenhouse soil. Sci. Rep. 2020, 10, 1-13. [CrossRef]

32. Bonkowski, M.; Roy, J. Soil microbial diversity and soil functioning affect competition among grasses in experimental microcosms. Oecologia 2005, 143, 232-240. [CrossRef] [PubMed]

33. Hazra, K.K.; Nath, C.P.; Singh, U.; Praharaj, C.S.; Kumar, N.; Singh, S.S.; Singh, N.P. Diversification of Maize-Wheat Cropping System with Legumes and Integrated Nutrient Management Increases Soil Aggregation and Carbon Sequestration. Geoderma 2019, 353, 308-319. [CrossRef] 
34. Zhang, Q.; Li, S.; Saleem, M.; Ali, M.Y.; Xiang, J. Biochar and Earthworms Synergistically Improve Soil Structure, Microbial Abundance, Activities and Pyraclostrobin Degradation. Appl. Soil Ecol. 2021, 168, 104154. [CrossRef]

35. Ruis, S.J.; Blanco-Canqui, H. Cover Crops Could Offset Crop Residue Removal Effects on Soil Carbon and Other Properties: A Review. Agron. J. 2017, 109, 1785-1805. [CrossRef]

36. Dozier, I.A.; Behnke, G.D.; Davis, A.S.; Nafziger, E.D.; Villamil, M.B. Tillage and Cover Cropping Effects on Soil Properties and Crop Production in Illinois. Agron. J. 2017, 109, 1261-1270. [CrossRef]

37. García-González, I.; Hontoria, C.; Gabriel, J.L.; Alonso-Ayuso, M.; Quemada, M. Cover Crops to Mitigate Soil Degradation and Enhance Soil Functionality in Irrigated Land. Geoderma 2018, 322, 81-88. [CrossRef]

38. Rillig, M.C.; Muller, L.A.; Lehmann, A. Soil Aggregates as Massively Concurrent Evolutionary Incubators. ISME J. 2017, 11, 1943-1948. [CrossRef]

39. Wang, B.; Brewer, P.E.; Shugart, H.H.; Lerdau, M.T.; Allison, S.D. Soil Aggregates as Biogeochemical Reactors and Implications for Soil-Atmosphere Exchange of Greenhouse Gases-A Concept. Glob. Chang. Biol. 2019, 25, 373-385. [CrossRef] 